rather one of organization, a real fibrillation of possible. Malignant tumors of the upper jaw the connective tissue. By means of this cicatricial present, therefore, but little to encourage an opercontraction the growth is greatly reduced in size. ation. When, furthermore, the removal of a ma-

It is evident that, as cell activity manifests it- lignant neoplasm. demands an operation in itself self in the growth of malignant tumors, so we see dangerous, the probability of success is small. cell life intimately associated with their decay and death.

Are malignant neoplasmata ever cured? If, in referring to malignant growths, we speak of effecting a cure, and mean thereby the internal administration of medicines which will aid a given part to resist the further invasion of the disease and to cast off the existing trouble, returning to its normal state, we surely must answer the question in the negative. No one speaks longer of malignant neoplasmata being the local expression of a constitutional taint. The disease begins in the very primitive cells of a part, and in its advance simulates most closely other infectious diseases of local origin. The question is, therefore, to be put in this manner: Can we ever so thoroughly eradicate a malignant tumor that in the future there shall be no recurrence of it locally, nor any remote manifestations attributable to its infection? This we certainly can answer affirmatively.

To say whether, in a given case, a favorable prognosis can be offered, requires a consideration of its period of existence, its seat, its anatomical and clinical characteristics, its extent, the local and constitutional complications, as well as the operative measures to be pursued. As the discussion of these important questions will fall to abler hands, it will only be necessary for me to briefly state a few established principles.

The greatest hope for the relief of malignant disease lies in its early thorough removal, while the disease is still very limited in extent, and before glandular infection is evident. As many cases have passed far beyond this stage before surgical attendance is solicited, the ultimate result is greatly imperiled. The primary location of a malignant tumor in an internal organ, where signs and symptoms of its existence are most obscure, or whenever its character cannot be well defined, as in the thyroid gland, early operation is out of the question.

A tumor which in a brief period of time has attained great size and exhibited unusually malignant tendencies, does not present as favorable an outlook for future exemption as does one whose growth has covered a long period, and where indications of local and general infection have long remained absent.

The occurrence of a primary growth in a part thoroughly accessible, and whose site forces its early recognition by the patient, leads to the most favorable results. Thus, in the lower lip 30 to 50 per cent. of the afflicted are cured. Appearing where with difficulty it can be entirely removed, its thorough eradication is all but im-
In his recent work upon "The Operative Surgery of Malignant Disease," Butlin strongly dedenounces the very serious but so-called brilliant operations of recent times for the relief of malignant disease. He refers to statistics of extirpation of the larynx, removal of malignant tumors of the kidney, of the uterus through the abdominal wall, cancerous thyroids, and so on, 364 cases in all, of whom 238 died in consequence of the operation. "Battles, shipwrecks and railroad accidents," says he, "are mild and merciful compared with some of these achievements of modern surgery." But it is not my intention to enter upon a discussion of operative procedures.

Without extending my remarks further, it can be safely said that where, by an operation, a malignant neoplasm which has not awakened secondary infection can be thoroughly removed, we may hope for permanent relief. True, people may after years again become the victims of malignant disease, just as they may twice have pneumonia; but the two attacks need not be more closely related to each other. Great loss of tissue or sacrifice of limbs may be necessary, but the disease is wholly removed.

A REPORT OF TWO CASES OF SCALDING OF THE AIR PASSAGES BY THE ACCIDENTAL INHALATION OF STEAM, WITH REMARKS.

Read before the Medical Society of the District of Columbia, June $13,1888$.

BY JOHN B. HAMILTON, M.D., SUPERVISING-SURGEON-GENERAL U. S. MARINE HOSPITAL SERVICE, PROFESSOR OF SURGERY IN GEORGETOWN UNIVERSITY, AND IN THE CHICAGO POLYCLINIC, ETC.

The following case fell under my observation in the Marine Hospital Ward of the Providence Hospital :

Captain Wharton, of the steam tug Clara Uhler, was brought to the hospital at 7:30 P.M., December I4, I883. It appeared on inquiry of the Pilot who accompanied him, that about 6 o' clock in the morning, the tug was lying in her berth at Shamrock Wharf, lower Potomac, and the Captain was asleep in his cabin, the engineer attempting to get under way, a pipe blew out and threw with great force the steam and hot water through the bulkhead on to the Captain and scalded him about the body, face and limbs, and he inhaled much of the steam. As the tug was disabled, the patient was compelled to wait four hours on board before he could proceed up the river. He arrived at Alexandria at 5 P.M. where a physician was sent for. He gave him a 
white powder, presumably morphia, and sent the patient hurriedly on to the hospital. On examining him, I found him in a state of collapse, his extremities were cold and pulseless, and his temperature was sub-normal. He was conscious but unable to speak, and his respiration was shallow and difficult. The facies hippocratica was well marked. I looked into his fauces and found the pharynx a white mass of scalded mucous membrane looking like a lining of cotton. Every effort was made to bring about reaction by the usual remedies, but the unfortunate man died in about two hours after admission to the hospital.

Case 2.- Inhalation of steam. Treatment by inhalation of dilute sulphuric ether; Recovery.-A male child, Geddis Crump, æt. 20 months, was playing in the kitchen of the house $22 \mathrm{D}$ Street, $\mathrm{N}$. W., on the evening of November 23, 1887 , and while so playing applied the spout of a teakettle to its mouth and suddenly inhaled a full inspiration of the steam from the kettle. The child immediately began struggling for air and rapidly grew worse. Dr. G. H. Wagner was sent for, and on his arrival found the child in great distress, stridulous breathing and cyanotic hue, struggling violently for air. The inside of the mouth and pharynx looked as if it were lined with cotton, Fearing œdema of the glottis, Dr. Wagner sent for me in consultation, and on my arrival an examination convinced me that the entire track of the lining of the pharynx, larynx, and trachea seemed involved. There was, therefore, no indication for the performance of tracheotomy as operation at the usual site could not relieve the diminished calibre of the air passages below. I, therefore, recommended the inhalation of ether for the double purpose of relieving the pain and arresting the spasm, but as the ether must be continued for some hours a diluent was necessary, and I used listerine; it is probable that an alcoholic solution of oil of juniper and cajuput might have answered an equally useful purpose, but the listerine was handy and no substitute occurred to me. Dr. Wagner administered the mixture, (ether I part, listerine 3 parts) and the pain was arrested, and the breathing became tranquil. He continued to use it through the night whenever the breathing became difficult, and had the satisfaction of seeing the child much better the next morning, and the inhalation was continued at intervals until about 4 P.M. Wednesday. At 9 P.M. on that day, the stridulous breathing again began, and the inhalations were continued until about midnight, after which there was no recurrence of the difficulty. During this time the child was nourished by means of weak milk punch. Steady improvement began, and by the following Monday the child was entirely well.

A hurried glance at the literature of the subject shows that these cases are not numerous, although Mr. Gant ${ }^{1}$ speaks of scalds of the larynx as frequent "among the children of the poor, in their attempting to drink from the spout of a kettle containing boiling water. The act of swallowing is not complete, but the inside of the mouth and pharynx are scalded, and cedema of the glottis is speedily induced; the interior of the lary nx remaining unaffected."

A somewhat similar statement is made by $\mathrm{Mr}$. Bryant, ${ }^{2}$ who in writing of scalds of the larynx, says: "This somewhat common accident is doubtless engendered amongst the poor by the habit of feeding their children out of a teapot. ${ }^{3}$ The child when thirsty and alone, being accustomed to drink from the spout, seeks it from the kettle, and so scalds the pharynx and orifice of the larynx, that cedematous inflammation of the part follows in the same way as a blister arises by the application of boiling water or stea m to any other tissue. The symptoms caused by such an accident appear, as a rule, very speedily, the small chink of the glottis soon closes, and as a consequence, a fatal result ensues, unless early relief can be obtained. In some cases the mouth, with the soft palate, tongue, and fauces will be found swollen and vesicated. There will be difficulty in swallowing, and some alteration in the character of the voice. The respiration rapidly becomes affected, and a spasmodic croupy cough appears with stridulous breathing. These symptoms may be complicated with attacks of spasmodic dyspnœa, at long or short intervals; but when these attacks appear extreme danger is indicated, any spasm possibly proving fatal."

Mr. Eddowes ${ }^{4}$ has reported a case of a severe scald of the mouth followed by oedema of the glottis. In this case tracheotomy was performed, but the child died on the fourth day after admission to the hospital. The post-mortem examination showed great venous congestion of the brain, and bubbles of air in the superficial veins of the membranes, some adhesions between the hemispheres, sero-purulent effusion between the dura arachnoid, and the lungs engorged with blood. The mucous surface of the trachea up to the larynx in a state of hyperæmia with appearance of purulent effusion. In the stomach there were two spots of sanguineous extravasation underneath mucous coat. The other organs were examined by Mr. Eddowes, but there is no note of any abnormality attributable to the injury.

A number of steamboat explosions have occurred in this country, in which scalded men have been admitted to the various Marine Hospitals, but it has only rarely happened that the mouth and larynx have been scalded in these accidents. It seems to depend upon the lo-

I Gant, Frederick James, (F.R.C.S.): The Science and Practice of Surgery, London, I87i.

872.

Bryant, Thomas (F.R.C.S.): The Practice of Surgery, London,

3 This statement seems to have originated with Marshall Hall, ide Med. Chirurg. 'Trans., Vol. xii, London, I822. 
cation of the men's berths, and on a majority of may, indeed, have almost entirely disappeared vessels, the forecastle is a safe distance from the when the section is made. ${ }^{10}$

boilers. Not so, however, on steam tugs and the smaller varieties of steam water-craft where economic reasons govern the location of the sleeping spaces.

In the harbor of Toulon, in 1859 , a steam pipe burst on the corvette "Le Roland," and a number of seamen were badly scalded, and in these cases there were some scalds of the mouth.

The treatment consisted of opiates internally, and the usual topical remedies. At the necropsies it was found that the tongue was denuded, red and bloody, and the muscular structure visible. The interior of the mouth and arches eroded, swelling of mucous membranes of air passages, and general congestion of the viscera. ${ }^{b}$

A somewhat similar condition is seen in the inhalation of hot smoke. Dr. Cohen ${ }^{6}$ relates a case he saw with Dr. Keen, where there had been an inhalation of hot smoke during the conflagration of a burning building. In this case there was "œdema of the larynx threatening suffocation, copious and frequent inhalations of the spray from a solution of the watery extract of opium relieved the suffering, and the patient eventually recovered."

In twenty-eight cases of scalds of the mouth, pharynx and glottis collected by Mr. Durham, twenty-three were fatal. (Ashurst.)

It must be evident on reflection that the lesions from the inhalations of steam, are more extensive, reaching further into the air passages than hot water or other fluids, and the same remark is applicable to those cases where in a burning building a flame is inhaled, In the case of caustic liquids or hot water the epiglottis, by falling down, protects the larynx, but this is rarely the case in the inhalation of steam, noxious gases, or flame.

As a medico-legal point, it is well to remember that severe internal congestions and reflex inflammations may supervene upon the injuries as well as upon those more extensive surface denudations. In short, says Taylor, ${ }^{8}$ besides congestion there is generally abundant serous effusion in one of the great cavities, especially in the head." Rokitansky $y^{\prime}$ has specially observed after burns of : the skin of the abdomen, that they "were in a few instances attended by fatal hæmorrhage from the bowels."

Treatment.-Let us now consider the important question of treatment in these cases. The indications are plain, to stop the pain and arrest the swelling. We cannot stop to assure ourselves that the burn is in one or another of the six degrees of Nèlaton, ${ }^{11}$ and then after classification adopt the remedy appropriate to the degree. The swelling of the lining membrane may entirely occlude the upper air passages in a few hours. The remedy then to be useful must be speedy in its operation. Such a remedy we have in sulphuric ether. This, it will at once be seen, acts in the double capacity of a local and general anæsthetic.

The use of ether as a topical dressing of burns is not new. Dr. Nunn ${ }^{12}$ refers to its use in recent burns on the surface of the body, superficial in character and limited in extent. He claimed that vesication was often prevented by commencing early, and steadily continuing its use until the pain ceased. Notwithstanding its irritating qualities, in case of the inability to procure ether, Dr. Nunn would use chloroform. The observation of Dr. Nunn in regard to burns on the surface of the body, is precisely in point, in the cases of scalds of the upper air passages, for the œdema follows the vesication, and if by the timely administration of the ether, vesication may be prevented, we have one of the most valuable therapeutic resources, and at the same time complete relief from the agonizing pain quite frequently the most prominent feature.

In my judgment, leeches to the outside of the throat, as recommended by certain text-books, will fail to exert any influence whatever in the arrest of odema. Both Mr. Gant and Mr. Bryant speak of this means of treatment, but Mr. Gant, regards it as valueless, and in regard to tracheotomy he views it as "only an alternative between death and the possible preservation of life, and that the operation is generally fatal from the supervention of bronchitis or pneumonia."

Mr. Bryant, after referring to the mild cases which scarcely require treatment, speaks of a case of a child "in whom these symptoms were so slight that no anxiety was felt, but one spasm (laryngeal) took place two hours and a half after the accident which put an end to life." When the laryngeal spasms are present, Mr. Bryant

In the post-mortem examination of cases of early resorts to tracheotomy. In some cases of burns of the mouth, we should remembe: that œdema after tracheotomy, he has found it adafter death the odema is less marked than during vantageous to puncture the epiglottis, and the life, and allowance must be made for that fact in , swollen laryngeal opening. An ordinary tenacudeciding on the immediate cause of death, for a lum he has found to answer every purpose, degree of swelling which involved danger to life, although several special instruments have been

5 Gaz. Med. de Paris, IS59, 35, xiv, p. 26-30.

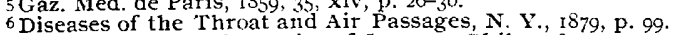

7 The Principles and Practice of Surgery, Phila., I87r, p. 345.

8 A Manual of Medical Jurisprudence, Phila., 1873, p. 377 .

A Manual of Pathological Anatomy, Philadelphia, 1855 , Vol. 3 , p. 74 .

Orth. A Compound of Diagnosis in Pathological Anatomy, N. Y., ${ }^{1878}$. Ir Nelaton, élemens de Pathologie Chirurgicale, I844, classified
rıs according to their severity, and phenomena: $a$. Local phenomena. Ist, 2d, 3d, 4th, 5th, and 6th degrees. $b$. General phenomena. Ist

'2 Charleston, M. J. \& Rev., 1855, x, 640. 
invented. The calomel treatment still finds ad- $\mid$ much as that disorder is spinal and may be caused vocates, and it is strongly probable that after the by an injury, the verdict against the road may acute period has passed, calomel may be of great have been perfectly just. Parallel cases are ciadvantage.

For some inscrutable reason mercurial inunction is still retained in the treatise on this subject as a useful remedy in cases of scalds of the mouth and larynx. If one believes with a noted old surgeon that all diseases originate in the liver, and therefore prescribe ipecac and blue pill for every thing, there is some sort of consistency in the practice, but with different views of pathology there is no good reason for the practice, which should be dropped from the text-books. Sponges wrung out of hot water are useful as a means of allaying pain after the danger of oedema has disappeared,

Ether treatment is the most promising, and I believe it will be found the most successful. It certainly cannot be much worse than the tracheotomy by Mr. Durham, where twenty-three out of twenty-eight cases perished after the operation from either bronchitis or pneumonia, and the ease and comfort given the patient is itself worth a great deal. The amount of dilution in any given case will be governed by the urgency of the case, and the age and strength of the patient, and the duration of its administration will depend entirely upon the pain and the tendency to laryngeal spasm.

After witnessing its very happy effects in the case just detailed, I certainly would place it first among the therapeutical resources in such cases.

\section{SPINAL CONCUSSION.}

BY S. V. CLEVENGER, M.D.,

CONSULTING PHYSICIAN FOR NERVOUS AND MENTAL DISEASES TO THE MICHAEL REESE AND ALEXIAN HOSPITALS, CHICAGO; MEMBER OF THE AMERICAN MICROSCOPICAL, AMERICAN ELECTRICAL SOCIETIES, ETC.

In THE JOURNAL of Dec. I 5, I 888, is published the Proceedings of the Chicago Medico-Legal Society of Oct. 6,1888 , beginning with a paper by Dr. James Burry, Surgeon to the C. S. F. \& C. Railroad, who states that within five years $\$$ I I , $00, \infty 00$ have been paid as damages by English railway companies in cases of alleged injury to the spinal cord, and $\$ 300$,000 to the Chatsworth sufferers, among whom spinal injury cases preponderated. This may seem hard upon the railroad companies, but it would not be reasonable to suppose that the courts would have awarded such sums unjustly in all cases. Imagine the Jay Goulds of the world free to coin millions from the traveling public, unhedged by any fear of damage suits for carelessness, incompetence, or brutal disregard of human life.

Dr. Burry cites the case of Waterman $v s$, the Chicago \& Alton R. R., wherein the defense was that the plaintiff had locomotor ataxia. Inas-

The case of Holland a's. the Chicago \& Eastern Illinois R. R. to my certain knowledge was a genuine and typical case of spinal concussion, and the verdict of $\$ 30,000$ awarded him was little enough for the complete demolition of his health and everything in life worth living for.

The Rozenzweig case i's. L. S. \& M. S. R. R, was evidently exemplary.

Dr. Steele's statement that Dr. Phillips was restored to health, "except for a slight lameness," after securing $\$ 80,000$ from the London \& Southwestern R. R., implies that the verdict was excessive, which, in the absence of details as to the general mental and physical condition of Dr. Phillips amounts to nothing. "Health" to the 'casual observer may be restored, but usually in such cases the abilities required of a practicing physician would be lost. Eirichsen's work is assailed as affording "overshadowing influence" and the erroneous pathological assumptions of that author are instanced against the general value of his book "Concussion of the Spine."

At the time Erichsen wrote, neurological pathology was undeveloped and so far as spinal concussion is concerned is still sub judice. It seemed justifiable to assume that organic lesions were behind the symptoms of the disease, inasmuch as extravasations and inflammatory changes in the cord produce allied neurotic conditions. If Erichsen went too far in guessing at the pathology of concussion he also states that "we should indeed be taking a limited view of the pathology of concussion of the spine if we were to refer all the symptoms, primary and remote, to inflammatory conditions, either of the vertebral column, the sheaths of the spinal nerves, the meninges of the cord or the substance of the medulla itself. Important and marked as may be the symptoms that are referable to such lesions as these that are primarily dependent on molecular changes in the cord itself, or spinal anæmia induced by the shock of the accident acting either directly on the cord itself, or indirectly, and at a later date, through the medium of the sympathetic, in consequence of which the blood distribution to the cord becomes disturbed and diminished."

The "molecular changes in the cord itself," which I have italicized above, constitute the cause of the symptoms at present assumed by pathologists, and Spitzka parallels it with the undemonstrable changes that devitalized the egg in railroad transit.

Surely it should not be claimed, when we do not know the pathology of a disease, that the disease itself does not exist, and yet in attacking the errors in pathology of Erichsen the clinical 